\title{
Gambling with esophageal cancer: May the odds be in your favor!
}

\author{
Ilkka K. Ilonen, MD, PhD, and Daniela Molena, MD
}

\author{
From the Division of Thoracic Surgery, Memorial Sloan Kettering Cancer Center, New York, NY. \\ Disclosures: Authors have nothing to disclose with regard to commercial support. \\ Ilonen and Molena contributed equally to this editorial. \\ Received for publication Feb 19, 2018; accepted for publication Feb 22, 2018; available ahead of print March 22, \\ 2018. \\ Address for reprints: Daniela Molena, MD, Thoracic Surgery Service, Department of Surgery, Memorial Sloan \\ Kettering Cancer Center, 1275 York Ave, New York, NY 10065 (E-mail: molenad@mskcc.org). \\ J Thorac Cardiovasc Surg 2018;156:404-5 \\ $0022-5223 / \$ 36.00$ \\ Copyright (c) 2018 by The American Association for Thoracic Surgery \\ https://doi.org/10.1016/j.jtcvs.2018.02.052
}

Endoscopic management of Barrett's esophagus with dysplasia and/or superficial esophageal cancer has significantly evolved within the last 20 years. Successful definitive management of superficial adenocarcinoma of the esophagus (T1a) with endoscopic mucosal resection (EMR) has been validated with minimal morbidity and remission rates greater than $90 \% .^{1}$ It may seem straightforward to extend the same type of treatment to submucosal tumors, because it is technically feasible and esophageal preservation is very appealing. When dealing with cancer, however, we should ask ourselves what we "should" do rather than what we "can" do, because undertreatment may have lethal consequences.

Patients with cancer invading the submucosa (T1b) and the muscularis propria (T2) have increased risk for regional nodal metastasis ${ }^{2,3}$; and because nodal disease cannot be successfully treated with endoscopic techniques, the use of therapeutic EMR for T1b tumors has been limited in the past to patients who are not candidates for esophagectomy. All T1b tumors, however, are not alike, and the concept of a "low risk" submucosal lesion has been recently described as a T1b tumor with a low risk of nodal involvement. ${ }^{4,5}$ Retrospective studies have in fact shown that well-differentiated or moderately differentiated tumors with only superficial involvement of the submucosa and absence of lymphovascular invasion have a low risk of nodal involvement $(<10 \%))^{5,6}$ Endoscopic treatment in these cases has resulted in a complete resection rate of $87 \%$ and estimated 5 -year survival of $84 \%$. $^{5}$

To pursue endoscopic therapy for T1 esophageal adenocarcinoma, the ability to predict likelihood of nodal metastasis becomes the key aspect of patient selection. For this reason, scoring systems have been developed to gauge the risk of nodal disease, with accuracy as great as $83 \% .^{4,7}$ It is important to point out that these scoring systems have been developed from esophagectomy specimens and have not been validated with clinical data. There are several limitations in our clinical staging system, which makes for nodal disease.

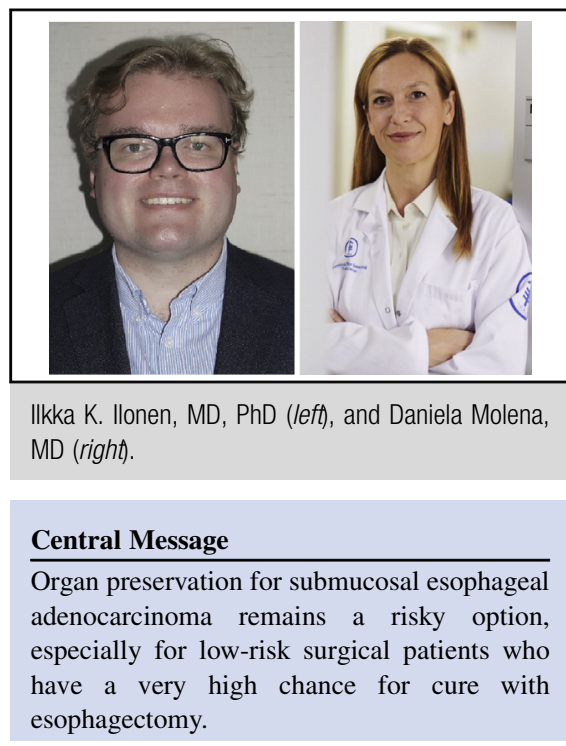

See Article page 406

our "guessing" with nodal disease much less accurate. Distinction between T1a and T1b tumors with endoscopic ultrasound evaluation has accuracy of $70 \%$ and sensitivity of $74 \%$ at best, ${ }^{8,9}$ and similar accuracy has been shown for assessment of nodal disease. ${ }^{10}$ It may seem that endoscopic ultrasound's limitations are easily overcome by pathologic evaluation of EMR specimens (diagnostic EMR); however a significant interobserver variability in EMR pathologic specimens has been shown even among expert gastrointestinal pathologists. ${ }^{11}$ Nevertheless endoscopic resection is the best staging tool available today for early stage cancer, because it will yield accurate information about the tumor size, depth of invasion, and presence of lymphovascular involvement, all of which are risk factors

Because there has not been a prospective randomized trial comparing esophagus-sparing strategies with esophagectomy in T1 esophageal adenocarcinoma, all published results have significant bias, most likely related to patient selection. Surgery is associated with major morbidity in $33 \%$ of cases and perioperative mortality of $3.4 \%{ }^{12}$; the number of patients needed to offset the initial burden of surgery to establish better long-term survival than EMR is therefore much higher than what is reported in retrospective series. It is important however to keep in mind that surgery alone is curative for patients with $\mathrm{T} 1 \mathrm{~b}$ tumors in a very high percentage of cases, even in patients with positive lymph 
nodes. In a recent multicenter study of patients with $\mathrm{T} 1 \mathrm{~b}$ disease staged with EMR and then treated with esophagectomy, disease-specific survivals at 5 years were reported as $88 \%$ overall, $100 \%$ in patients with negative lymph nodes, and $67 \%$ for node-positive disease. ${ }^{13}$

In their retrospective study in this issue of the Journal, Nelson and colleagues ${ }^{14}$ showed that local recurrence after EMR for T1b tumors was $23.1 \%$, versus $0 \%$ after esophagectomy, which is in line with previously reported outcomes. ${ }^{15,16}$ No differences were noted in regional or distal metastasis between the groups, however, during a median follow-up of 3.5 years. Unlike the previously reported study by Manner and associates, ${ }^{5}$ that of Nelson and colleagues ${ }^{14}$ included high-risk patients treated with EMR. Moreover, this is one of the only studies to compare surgery against EMR directly. Unfortunately, the study was not powered to give full resolution to end points, including overall survival and regional and distal recurrence. Although lacking statistical significance, however, surgery faired better than EMR in all the curves shown in this study, even if the esophagectomy group included a larger percentage of "highrisk" lesions. A disease-free survival just greater than $60 \%$ for $\mathrm{T} 1 \mathrm{~b}$ adenocarcinoma treated with endoscopic resection is very worrisome, especially since more than $70 \%$ patients had what is considered a "low-risk" lesion. Even more concerning is a distant recurrence rate of $13 \%$ in these patients, highlighting that a rescue esophagectomy is often not possible. On the other hand, half of the patients who underwent esophagectomy after successful EMR had no residual disease on pathologic examination, and these patients might have been overtreated with an esophagectomy. Overtreatment, however, may carry a lower life cost than undertreatment in a specialized and high-volume center, as testified by the $0 \%$ mortality reported by Nelson and colleagues. ${ }^{14}$ Moreover, it would be interesting to know whether the patients with no residual disease on pathologic examination had a high- or low-risk lesion and whether they had an endoscopic resection with a negative deep margin to make them even eligible for organ-sparing approach.

\section{CONCLUSIONS}

EMR is a useful tool to obtain high-quality samples of both T1a and T1b tumors, which will facilitate individual treatment planning for each patient. Esophagectomy offers high likelihood of cure for patients with T1b tumors, even in the presence of nodal metastases. Surgery, however, is associated with not insignificant morbidity, a $3 \%$ to $4 \%$ chance of mortality, and lifestyle changes. Endoscopic therapy offers the great advantage of organ sparing, low morbidity, and virtually no mortality. The trade-off, however, is the potential of leaving untreated disease behind, which will recur locally, regionally, or, at worst, systemically. Discriminating patients with more aggressive disease is still a gamble with an accuracy of $85 \%$ in the best-case scenario.
Although $85 \%$ winning rate may seem very satisfying for sport betting, it means potentially losing the battle to cancer in a high percentage of cases with at least 3-fold higher mortality than that associated with esophagectomy. Until we delineate better algorithms for patient selection and followup for esophagus-sparing approach, the decision to treat patients with a T1b tumor with endoscopic therapy must be made in a multidisciplinary fashion, with patients understanding the risk and the implication of increased local recurrence and potentially unrecognized regional nodal disease.

\section{References}

1. Pech O, May A, Manner H, Behrens A, Pohl J, Weferling M, et al. Long-term efficacy and safety of endoscopic resection for patients with mucosal adenocarcinoma of the esophagus. Gastroenterology. 2014;146:652-60.e1.

2. Leers JM, DeMeester SR, Oezcelik A, Klipfel N, Ayazi S, Abate E, et al. The prevalence of lymph node metastases in patients with T1 esophageal adenocarcinoma: a retrospective review of esophagectomy specimens. Ann Surg. 2011;253: 271-8.

3. Nigro JJ, Hagen JA, DeMeester TR, DeMeester SR, Peters JH, Oberg S, et al. Prevalence and location of nodal metastases in distal esophageal adenocarcinoma confined to the wall: implications for therapy. J Thorac Cardiovasc Surg. 1999; 117:16-23; discussion 23-5

4. Lee L, Ronellenfitsch U, Hofstetter WL, Darling G, Gaiser T, Lippert C, et al. Predicting lymph node metastases in early esophageal adenocarcinoma using a simple scoring system. J Am Coll Surg. 2013;217:191-9.

5. Manner H, Pech O, Heldmann Y, May A, Pohl J, Behrens A, et al. Efficacy, safety, and long-term results of endoscopic treatment for early stage adenocarcinoma of the esophagus with low-risk sm1 invasion. Clin Gastroenterol Hepatol. 2013;11: 630-5.

6. Boys JA, Worrell SG, Chandrasoma P, Vallone JG, Maru DM, Zhang L, et al. Can the risk of lymph node metastases be gauged in endoscopically resected submucosal esophageal adenocarcinomas? A multi-center study. J Gastrointest Surg. 2016;20:6-12; discussion 12.

7. Weksler B, Kennedy KF, Sullivan JL. Using the National Cancer Database to create a scoring system that identifies patients with early-stage esophageal cance at risk for nodal metastases. J Thorac Cardiovasc Surg. 2017;154:1787-93.

8. He LJ, Shan HB, Luo GY, Li Y, Zhang R, Gao XY, et al. Endoscopic ultrasonography for staging of T1a and T1b esophageal squamous cell carcinoma. World J Gastroenterol. 2014;20:1340-7.

9. Dhupar R, Rice RD, Correa AM, Weston BR, Bhutani MS, Maru DM, et al. Endoscopic ultrasound estimates for tumor depth at the gastroesophageal junction are inaccurate: implications for the liberal use of endoscopic resection. Ann Thorac Surg. 2015;100:1812-6.

10. Pech O, Günter E, Dusemund F, Origer J, Lorenz D, Ell C. Accuracy of endoscopic ultrasound in preoperative staging of esophageal cancer: results from a referral center for early esophageal cancer. Endoscopy. 2010;42:456-61.

11. Worrell SG, Boys JA, Chandrasoma P, Vallone JG, Dunst CM, Johnson CS, et al Inter-observer variability in the interpretation of endoscopic mucosal resection specimens of esophageal adenocarcinoma: interpretation of ER specimens. J Gastrointest Surg. 2016;20:140-4; discussion 144-5.

12. Raymond DP, Seder CW, Wright CD, Magee MJ, Kosinski AS, Cassivi SD, et al. Predictors of major morbidity or mortality after resection for esophageal cancer: a Society of Thoracic Surgeons General Thoracic Surgery Database risk adjustment model. Ann Thorac Surg. 2016;102:207-14.

13. Molena D, Schlottmann F, Boys JA, Blackmon SH, Dickinson KJ, Dunst CM et al. Esophagectomy following endoscopic resection of submucosal esophageal cancer: a highly curative procedure even with nodal metastases. J Gastrointest Surg. 2017;21:62-7.

14. Nelson DB, Dhupar R, Katkhuda R, Correa A, Goltsov A, Maru D, et al. Outcomes after endoscopic mucosal resection or esophagectomy for submucosa esophageal adenocarcinoma. J Thorac Cardiovasc Surg. 2018;156:406-13.

15. Guo HM, Zhang XQ, Chen M, Huang SL, Zou XP. Endoscopic submucosal dissection vs endoscopic mucosal resection for superficial esophageal cancer World J Gastroenterol. 2014;20:5540-7.

16. Ballard DD, Choksi N, Lin J, Choi EY, Elmunzer BJ, Appelman H, et al. Outcomes of submucosal (T1b) esophageal adenocarcinomas removed by endoscopic mucosal resection. World J Gastrointest Endosc. 2016;8:763-9. 